\title{
Upaya Meningkatkan Keterampilan Teknik Dasar Shooting Dalam Permainan Sepak Bola Melalui Penerapan Gaya Mengajar Drill Dan Pendekatan Bermain Pada Siswa Kelas Iv-A SD Yayasan Pendidikan Nurul Hasanah Tahun Ajaran 2020/2021
}

\section{Muhammad Zaki ${ }^{1}$, Dewi Maya Sari ${ }^{2}$}

1,2 Sekolah Tinggi Olahraga dan Kesehatan Bina Guna, Indonesia

Jl. Aluminium Raya No. 77, Tanjung Mulia, Medan, Sumatera Utara

Email : mhdzaki01@gmail.com

\begin{abstract}
ABSTRAK
Penelitian ini merupakan Penelitian Tindakan Kelas (PTK). Penelitian ini dilakukan dalam dua siklus, terdiri dari empat tahap dalam setiap siklusnya yang terdiri dari tahap perencanaan, pelaksanaan tindakan, observasi dan refleksi. Subyek penelitian tindakan kelas ini adalah siswa kelas IV-A SD Yayasan Pendidikan Nurul Hasanah Tahun Ajaran 2020/2021 yang berjumlah 34 orang siswa dengan perincian 20 siswa putra dan 14 siswa putri. Sumber data dalam penelitian ini berasal dari siswa, peneliti dan guru yang bertindak sebagai kolaborator. Teknik pengumpulan data menggunakan tes. Penelitian tindakan Kelas ini menggunakan teknik analisis data secara deskriptif kualitatif dengan teknik prosentase untuk melihat kecenderungan yang terjadi dalam kegiatan pembelajaran. Hasil penelitian menunjukan bahwa penerapan gaya mengajar drill dan pendekatan bermain mampu meningkatkan keterampilan teknik dasar shooting dalam permainan sepak bola pada siswa kelas IV-A SD Yayasan Pendidikan Nurul Hasanah Medan Tahun Ajaran 2020/2021. Hal ini sejalan dengan hasil data temuan yang diperoleh peneliti pada kondisi awal pra siklus ke siklus I sampai akhir siklus II. Persentase nilai ketuntasan keterampilan teknik dasar shooting dalam permainan sepak bola siswa kelas kelas IV-A SD Yayasan Pendidikan Nurul Hasanah Medan pada kondisi awal pra siklus sebesar (11.77\%) atau sejumlah 4 siswa yang mencapai ketuntasan belajar dari 34 siswa keseluruhan, kemudian pada siklus I diperoleh nilai ketuntasan sebesar (55.88\%) atau sejumlah 19 siswa dan pada akhir siklus II meningkat sebesar (85.29\%) atau sejumlah 29 siswa yang mencapai ketuntasan belajar. Hal ini sejalan dengan adanya peningkatan keterampilan shooting dalam permainan sepak bola siswa kelas IV-A SD Yayasan Pendidikan Nurul Hasanah Medan yang ditunjukkan dari keaktifan dalam mengikuti proses pembelajaran dengan baik.
\end{abstract}

\section{Kata kunci: Teknik Dasar Shooting, Drill dan Pendekatan Bermain}

\begin{abstract}
This research use Class Action Research. This research is done by using two cycles, consists of four steps, every cycle consists of planning, action, observation, and reflection. Subject in this research is students at IV-A class in SD Yayasan Pendidikan Nurul Hasanah Academic Year 2020/2021, which is amounted 34 students, 20 men and 14 women. Source of the data in this research from student, researcher and teacher which has functioned as a colaborator. Technique of Collecting Data used test. Class Action Research uses data analysis by using descriptive qualitative with percent technique for looking the process of learning. The result research shows that applying drill teaching and playing approach are able to improve shooting technique skill for playing football at SD Yayasan Pendidikan Nurul Hasanah Grade
\end{abstract}


IV-A Academic Year 2020/2021. It is indicated that the data that found by the researcher for the first in pre-cycle to cycle I till to cycle II. The percent of result for improving basic of shooting technique skill in playing football through applying drill teaching and playing approach at SD Yayasan Pendidikan Nurul Hasanah Grade IV-A, the first condition in precycle is $(11.77 \%)$ or 4 students are success in learning process from the all students (34 students), then for the first cycle in this research found, the student which mastery learning is (55.88\%) or 19 students and for the last cycle, it can be gotten the high score is (85.29\%)or 29 students which is mastery learning. This is indicated that Improving Basic of Shooting Technique Skill for Playing Football through Applying Drill Teaching and Playing Approach at SD Yayasan Pendidikan Nurul Hasanah Grade IV-A Academic Year 2020/2021 can be better than before.

\section{Keywords: Basic of Shooting Technique, Drill and Playing Approach}

\section{PENDAHULUAN}

Sebagai aktifitas yang sangat digemari permainan bola kaki ini berbeda dengan proses pembelajaran yang ada di sekolah, disetiap aktifitas dalam proses pembelajaran terlihat sangat monoton sehingga para siswa kurang tertarik untuk mengikuti aktifitas yang diberikan. Dalam proses pembelajaran seorang guru dituntut untuk inovatif menyajikan proses pembelajaran dan menarik perhatian siswa untuk lebih tertarik mengikuti aktifitas tersebut. Seorang guru harus mampu memanfaatkan media-media belajar dan penggunaan metode yang tepat agar siswa mampu menguasai materi yang diberikannya. Bola kaki termasuk kedalam salah satu materi yang diajarkan pada mata pelajaran pendidikan jasmani kelas IV SD Yayasan Pendidikan Nurul Hasanah dan salah satu yang menjadi materi tersebut adalah shooting. Shooting bagian yang tidak terpisahkan dalam permainan sepak bola dan penting bagi pemain individu dan tim.

Dari hasil observasi pendahuluan yang dilakukan di SD Yayasan Pendidikan Nurul Hasanah, dinyatakan bahwa keterampilan siswa dalam melakukan shooting pada pemainan sepak bola masih rendah, siswa sering mengalami kesulitan dalam membuat gol saat pertandingan, akurasi tendangan siswa yang kurang akurat serta gaya mengajar yang menoton sehingga membuat proses pembelajaran kurang tersampaikan dengan maksimal, hal ini dapat dilihat dari rata-rata ketuntasan pelajaran pendidikan jasmani yang belum memenuhi KKM (Kriteria Ketuntasan Minimal) yaitu 75. Khususnya siswa kelas V yang berjumlah 34 siswa yang mampu melakukan shooting dengan baik hanya 4 orang, berarti dari data tersebut hanya $11.77 \%$ dari siswa seluruhnya yang berhasil menguasai teknik dasar shooting dalam permainan sepak bola. Jadi nilai ini belum memenuhi kriteria ketuntasan minimal secara klasikal yang ditetapkan yaitu 85\% dari keseluruhan siswa.

Hal seperti ini tentunya tidak bisa dibiarkan terus berlarut. Hal ini dapat disebabkan oleh banyak faktor yang mempengaruhi siswa tersebut dalam melakukan shooting, diantaranya adalah, (1) siswa tersebut jarang bermain sepak bola pada waktu-waktu yang senggang dalam kesehariannya sehingga aspek motoriknya dalam bermain menjadi kurang terasah, (2) siswa tersebut malu bermain sepak bola karena banyak teman yang memperhatikannya saat bermain sepak bola sehingga membuat siswa tersebut grogi, malu bahkan menjadi takut, hal ini dapat membuat gerak siswa tersebut menjadi setengah-setengah sehingga tidak maksimal, (3) siswa tersebut asal-asalan dalam bermain sepak bola dengan peralatan 
yang dianggap sudah biasa, hal ini membuat perasaan siswa menjadi hal yang sudah biasa untuk bermain sepak bola.

Seorang pendidik selayaknya memiliki metodologi mengajar, karena keberhasilan Proses Belajar Mengajar (PBM) bergantung pada cara mengajar gurunya. Jika cara mengajar gurunya menarik menurut siswa, maka siswa akan tekun, rajin, antusias menerima pelajaran yang diberikan, sehingga diharapkan akan terjadi perubahan dan tingkah laku pada siswa baik tutur katanya, sopan santunnya, motorik dan gaya hidupnya. Ada banyak metode pengajaran yang dapat digunakan oleh para pendidik untuk meningkatkan hasil belajar shooting dalam permainan sepak bola dan salah satunya dengan menggunakan gaya mengajar drill.

Gaya mengajar drill merupakan metode yang mengajarkan siswa untuk melaksanakan kegiatan latihan agar siswa memiliki ketegasan atau keterampilan yang lebih tinggi dari pada hal-hal yang telah dipelajari. Di samping menggunakan gaya mengajar drill, upaya lain yang dianggap mampu menumbuhkan semangat siswa, dengan pendekatan bermain. Bentuk penyajian bermain tidak hanya berpengaruh terhadap bermain tetapi dapat digunakan untuk latihan kekuatan otot, kelenturan, bahkan untuk latihan keterampilan motorik dan pembentukan pribadi siswa. Guru dalam memilih jenis permainan yang sesuai harus mempertimbangkan tahap perkembangan siswa, kebutuhan siswa serta keadaan siswa. Dengan demikian seorang guru harus mengetahui tentang tahap-tahap perkembangan siswa, dengan harapan dapat memilih bentuk penyajian permainan. Permainan gawang tong merupakan salah satu alternatif pembelajaran shooting permainan sepak bola di sekolah. Adapun alasan yang mendasari pemilihan judul tersebut adalah sebagai berikut: 1. Dengan menggunakan gawang tong anak yang tadinya susah memasukkan bola ke gawang menjadi lebih bersemangat karena gawang yang tidak seperti biasanya terbuat dari kardus yang disusun dipinggir lapangan, 2. Melatih kekuatan otot kaki pada saat menendang bola 3. Tercapainya azas landasan penjaskes: a. Dari yang sukar menuju ke yang mudah, b. Dari yang tidak bisa menjadi bisa, c. Dari sakit menjadi yang tidak sakit, d. Dari yang biasa menjadi yang kompleks.

Peneliti berharap agar penggunaan permainan gawang tong lebih diberdayakan karena dengan media tersebut mampu meningkatkan minat siswa terhadap materi yang disampaikan, dan yang lebih penting tujuan yang telah ditetapkan tersebut bisa tercapai. Penggunaan media pembelajaran terutama yang berhubungan dengan pemanfaatan teknologi, secara langsung bisa meningkatkan kualitas/kompetensi yang dimiliki oleh guru tersebut.

\section{METODE PENELITIAN}

Subyek penelitian tindakan kelas ini adalah siswa kelas IV-A SD Yayasan Pendidikan Nurul Hasanah Tahun Ajaran 2020/2021 yang berjumlah 34 orang siswa dengan perincian 20 siswa putra dan 14 siswa putri. Jenis penelitian yang digunakan adalah PTK (penelitian tindakan kelas), yaitu penelitian yang bertujuan memberikan sumbangan nyata peningkatan profesionalisme guru, menyiapkan pengetahuan, pemahaman dan wawasan tentang prilaku guru pengajar dan siswa belajar. Pada intinya PTK merupakan suatu penelitian yang akar permasalahannya muncul dikelas dan dirasakan langsung oleh guru yang bersangkutan sehingga sulit dibenarkan jika ada anggapan bahwa permasalahan dalam tindakan kelas diperoleh dari persepsi atau lamunan seorang peneliti Arikunto (2006:16). Dengan 
demikian penelitian tindakan kelas (Classroom Action Research) terkait dengan persoalan praktik pembelajaran sehari-hari yang dihadapi oleh guru.

Sukardi (2003:75) menyatakan bahwa instrumen adalah merupakan alat atau fasilitas yang digunakan peneliti dalam mengumpulkan data penelitian. Sebagaimana yang diungkapkan oleh Sukardi bahwa instrument adalah alat untuk memperoleh data yang diperlukan ketika peneliti menginjak pada hubungan informasi di lapangan. Instrumen penelitian yang digunakan dalam penelitian tindakan kelas ini adalah tes.

\section{Kisi-Kisi Instrumen Keterampilan Shooting Dalam Permainan Sepak Bola}

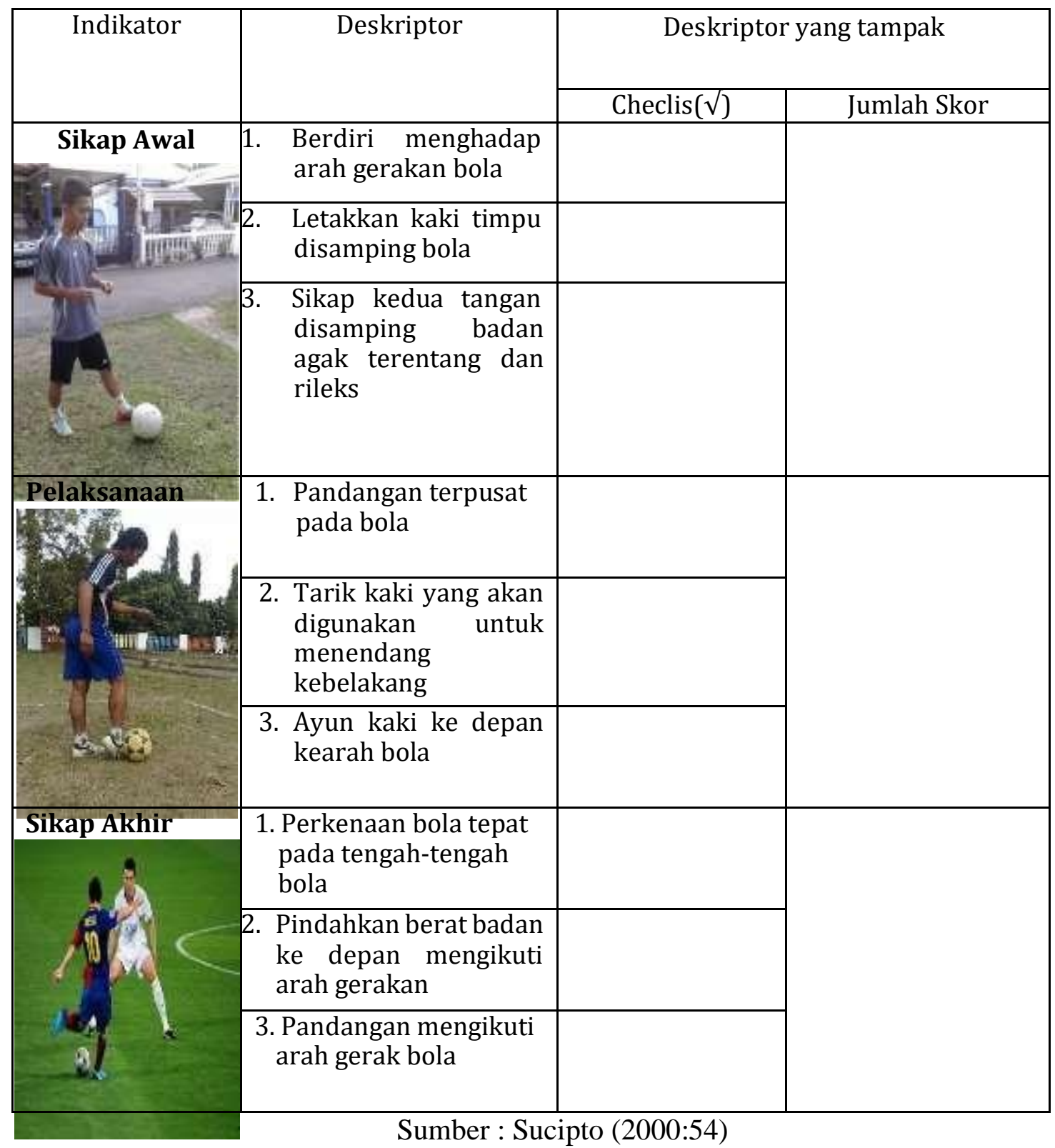

\section{HASIL DAN PEMBAHASAN}


Berdasarkan hasil pelaksanaan tindakan pada siklus I dan II dapat disimpulkan bahwa terjadi peningkatan keterampilan teknik dasar shooting pada permainan sepak bola siswa kelas IV-A SD Yayasan Pendidikan Nurul Hasanah Medan. Pada pratindakan nilai ratarata keterampilan teknik dasar shooting dalam permainan sepak bola yaitu 49.01, sesudah diberi perlakuan siklus I rata-rata keterampilan teknik dasar shooting dalam permainan sepak bola yaitu 68.94, sedangkan setelah mendapat perlakuan dalam siklus II memiliki ratarata keterampilan teknik dasar shooting dalam permainan sepak bola yaitu 74.82. Berdasarkan data tersebut menggambarkan, rata-rata keterampilan teknik dasar shooting dalam permainan sepak bola siswa kelas IV-A SD Yayasan Pendidikan Nurul Hasanah Medan dari kondisi awal ke siklus I dan siklus II mengalami peningkatan yang cukup baik. Hal ini dapat dilihat bahwa, rata-rata mengalami peningkatan dari kondisi awal ke siklus I dan siklus II.

\section{KESIMPULAN}

Berdasarkan dari hasil pembahasan penelitian maka dapat ditarik kesimpulan bahwa: Penerapan gaya mengajar drill dan pendekatan bermain mampu meningkatkan keterampilan teknik dasar shooting dalam permainan sepak bola pada siswa kelas IV-A SD Yayasan Pendidikan Nurul Hasanah Medan Tahun Ajaran 2020/2021. Hal ini sejalan dengan hasil data temuan yang diperoleh peneliti pada kondisi awal pra siklus ke siklus I sampai akhir siklus II. Persentase nilai ketuntasan keterampilan teknik dasar shooting dalam permainan sepak bola siswa kelas kelas IV-A SD Yayasan Pendidikan Nurul Hasanah Medan pada kondisi awal pra siklus sebesar (11.77\%) atau sejumlah 4 siswa yang mencapai ketuntasan belajar dari 34 siswa keseluruhan, kemudian pada siklus I diperoleh nilai ketuntasan sebesar (55.88\%) atau sejumlah 19 siswa dan pada akhir siklus II meningkat sebesar (85.29\%) atau sejumlah 29 siswa yang mencapai ketuntasan belajar. Hal ini sejalan dengan adanya peningkatan keterampilan shooting dalam permainan sepak bola siswa kelas IV-A SD Yayasan Pendidikan Nurul Hasanah Medan yang ditunjukkan dari keaktifan dalam mengikuti proses pembelajaran dengan baik.

\section{DAFTAR PUSTAKA}

Arikunto, S. dkk. 2006. Penelitian Tindakan Kelas. Jakarta: Bumi Aksara.

Asmani, J.M. 2009. Jurus-Jurus Belajar Efektif untuk SMP dan SMA. Yogjakarta: Diva press.

Aditya, R., \& Azandi, F. (2020). Effect of Play Approach Against Learning Outcomes in Soccer Games. JPJ (Jurnal Pendidikan Jasmani), 1(1), 1-7.

Djajadisastra, Jusuf. 2002. Metode-metode Mengajar. Bandung: Angkasa.

Hamdani. 2009. Strategi Belajar Mengajar. Bandung: Pustaka Setia.

Helmy Firmansyah. 2009. Hubugan Motivasi Berprestasi Siswa dengan Hasil Belajar Pendidikan Jasmani. Jurnal JPJI.

Kosasih, Engkos. 2005. Olahraga Teknik dan Program Pelatihan. Jakarta: Tiga Serangkai. 
Samsudin. 2008. Pembelajaran Pendidikan Jasmani Olahraga dan Kesehatan SMP/MTs. Litera Pranada Media Grup. Jakarta: Bumi Aksara.

Soekatamsi. 2005. Teknik Dasar Bermain Sepak Bola. Surakarta: Tiga Serangkai.

Soni, Nopembri. 2005. “Teknik Menendang Bola dengan Kaki Bagian Dalam. Jakarta. Jurnal Ilmiah Olahraga. 11 (7): 65- 78.

Sucipto, Bambang Sutiyono, Indra M. Thohir \& Nurhadi. 2000. Sepak Bola. Jakarta: Depdikbud.

Sudijandoko, Andun. 2010. “Penerapan Teknik Shooting dalam Permainan Sepak Bola. Yogyakarta. Pendidikan Jasmani Indonesia”, 7 (3): 20-35.

Suherman, Adang. 2000. Dasar-Dasar Penjaskes. Jakarta: Depdikbud.

Sukardi. 2003. Metodologi Penelitian Pendidikan Kompetensi dan Prakteknya. Jakarta: Bumi Aksara.

Sukintaka. 2004. Teori Pendidikan Jasmani;Filosofi Pembelajaran \& Masa Depan. Bandung: Nuansa Cendikia.

Suryosubroto. B. 1997. Proses Belajar Mengajar Di Sekolah. Jakarta: Rineka Cipta.

Tarigan, Beltasar. 2001. Pendekatan Keterampilan Taktis Dalam Pembelajaran. Sepak Bola. Jakarta: Depdiknas.

Wahjoedi. 2009. "Teknik dalam Permainan Sepak Bola”. Jakarta. Jurnal Iptek Olahraga, 16 (6): 34-38. 